\title{
Exploration of Medical Students' Health Literacy Cultivation under the Strategy of "Healthy China"
}

\author{
Jin WANG \\ School of Marxism, Xi'an Medical University, No.1 Xinwang Rd.,Weiyang Dist., Xi'an, PR China, \\ 710021
}

Keywords: Healthy China, Medical students, Health literacy.

\begin{abstract}
As a special group in the "healthy China" strategy, medical students are playing an important part to spread health knowledge and concepts and to improve the health literacy of Chinese people. This paper attempts to clarify the inevitability of the cultivation of medical students' health literacy, to summarize the reasons for the lack of the cultivation of health literacy in medical colleges and universities, and suggests that medical schools should update educational concepts as soon as possible, attach importance to the whole process of cultivation of medical students' health literacy, train qualified medical talents that are compatible with the "Healthy China" strategy by health literacy curriculum and "second class" construction.
\end{abstract}

\section{Introduction}

The construction of Healthy China is an important foundation for building a moderately prosperous society in all respects in China. In 2016, China promulgated the "Healthy China 2030 Plan", which clarifies that the strategic theme of healthy China is "participation by all and benefits to all, health for all", proposing to strengthen personal health responsibilities, to improve the national health literacy, and to guide the formation of a healthy lifestyle that is self-disciplined and consistent with its own characteristics, and effectively to control the factors affecting the healthy life behavior. In 2017, General Secretary Xi Jinping again emphasized the "Implementation of a Healthy China Strategy" in his reports to the 19th National Congress of the Communist Party of China, in which he said that we should adhere to prevention first, carry out the patriotic health campaign in depth, advocate a healthy and civilized lifestyle, and prevent and control major diseases [1]. The strategic thinking of "Healthy China" entails that the focus of China's national health dreams in the new era will shift from the treatment of diseases to the prevention of diseases. National health not only reflects the state's ability to fight diseases but also the ability to prevent diseases, the cultivation of public health concepts, healthy lifestyles, and healthy behavioral practices. The professional characteristics and professional nature of medical students determine that the cultivation of their health literacy should be higher than the ordinary people both in depth and breadth, and play a leading role in promoting the national health literacy.

\section{The Necessity of Cultivating Health Literacy for Medical Students}

\section{The Connotation of Health Literacy}

In 1998, the World Health Organization defined health literacy from the perspective of public health: health literacy is a manifestation of cognitive and social skills, determining the ability and motivation of individuals to obtain, understand, and use information in order to promote and maintain a good health [2]. Health literacy is an ability, which is composed of cognitive ability and social skills, is a comprehensive ability combining concept, theory and practice to achieve the unity of knowledge and practice. The manifestation of health literacy is the individual's comprehensive ability. In the theoretical model of health literacy put forward by Don Nutbeam in 2000, he mentioned three levels of health literacy: functional health literacy, communicative health literacy, and evaluation health literacy, representing the cognitive abilities and skills of an individual. [3]

Health literacy involves not only individual's basic cognitive ability of learning, understanding, 
and expressing health knowledge and information, but also the individual's ability to effectively disseminate health knowledge, communication and communication skills, and the ability to obtain health information and identify health information, the ability to improve personal health and the ability to engage in health services.

\section{The Reform of Medical Education Concept Caused by the Change of Medical Model}

Traditional medical model has been transformed from a purely biomedical model to a "biological-psychological-social medical" model. China is also gradually exploring a new type of medical and health service model that integrates medical treatment, health care, prevention, and rehabilitation. The change of the medical model requires that the concept of medical education should be changed from disease treatment to prevention first, and the service target needs to be transformed from the patient to the entire population [4]. Medical students as a backbone force for the implementation of the "Healthy China" strategy should have a higher level of health literacy than ordinary people. The purpose of nurturing health literacy is to guide medical students from focusing on diseases, paying attention to medical skills to focusing on public health in a broader sense, from paying attention to patients to paying attention to the entire population, to guide medical students to master health knowledge, cultivate health awareness, and improve their health education and health management capabilities. Therefore, the cultivation of medical students' health literacy reflects not only a higher level of humanistic care, but also a concentrated reflection of medical education and quality training.

\section{Internalization of Health Literacy: Requirements for Qualified Medical Students}

In 2001, the Chinese Medical Foundation of the United States (CMB) formulated the "Minimum Basic Requirements for Medical Education in the World", including seven macro teaching results and areas of competence, among which the training requirements of three groups: group health and health systems, information management, critical thinking and research, have a close relationship with health literacy.

The group health and hygiene system clearly states that medical graduates should be aware of the role they should play in protecting and promoting human health and can take appropriate actions to have a basic understanding of the effective and efficient management of the health care system. The cultivation of health literacy is conducive to medical students engaged in health promotion and health management in the future.

Information management means that medical graduates have the ability to collect, analyze, judge, and manage medical information. The object of information management should be generalized medical service information, including both disease treatment information and information on disease prevention, health care and rehabilitation. The cultivation of medical students' health literacy enriches the connotation of this ability.

Critical thinking and research means that medical graduates should critically evaluate existing knowledge, technology, and information, have the ability to think scientifically and to use medical methods scientifically, have the ability to educate patients and the public about health, illness, risk factors, have the ability to advice and counsel. This critical thinking and research ability is in common with critical health literacy, which is the highest level of health literacy. It is the organic integration of cognitive and practical skills that directly affects the effectiveness of health education.

\section{The Benefit of Cultivation of Medical Students' Health Literacy to Improve Health Communication}

Functioning as a media of spreading health information to the public in the future, students of medical colleges and universities are in a critical period of learning health knowledge and skills, in the key period of forming and steadily developing concepts and behaviors for their future career development, and their health literacy has attracted much attention [5]. We are about to usher in a new era of accurate health communication. Medical workers with medical literacy, scientific 
literacy and media literacy are greatly in need to ensure the scientific and authoritative health information on the front line of information spreading. The first two qualities are dependent on the establishment of great health concepts in medical education, the study of professional knowledge and skills, and the development of healthy thinking and behavior.

\section{Current Situation of the Health Literacy Education in Medical Colleges and Universities}

At present, the level of medical literacy among medical students is low, and medical colleges are lagging behind in their understanding of the cultivation of medical student' health literacy. The "disease-centered" and "patient-centered" old thinking model also hampers the minds of medical educators and college administrators. The role of "healthy China" strategy in the transition of medical colleges and medical students is not yet clear. The "national health-oriented, people-centered" medical education reform needs to be vigorously promoted.

\section{Insufficient Awareness of the Cultivation of Health Literacy}

Medical colleges and universities have not yet formed their own education concept that matches the "Healthy China" strategy, and a mature concept of great health education is badly needed to be established. The systematic education around health promotion, health education and health management is lagging behind, and the reform, linked to target of "big health, great health, and big data" in the new era, of talents training, scientific research, and health service education is advancing slowly.

\section{The Narrow Sense of Medical Humanistic Education in the Cultivation of Medical Students' Health Literacy}

The cultivation of medical students' health literacy cannot be simply equated with medical humanistic education. The professional spirit education, medical ethics education, and doctor-patient communication skills training only focus on the cultivation of humanistic spirits, which is distinguishable from broader ideas on health education. The cultivating of medical students' literacy is integration of medical humanities education, health humanities education and professional education.

\section{The Vacancy of Health Literacy Curriculum and the Fragmented Health Literacy Education}

Currently, the medical literacy curriculum system is vacant, and the disease prevention, health education, rehabilitation medicine, and information management related courses connected with health literacy education are monotonous and not opened to all majors, and they are not yet integrated into the general medical education system. Some related elected courses are not available yet now due to the weak teaching staff.

\section{The Lack of Research on the Contents of Teaching Health Literacy in the "Second Class"}

There are almost no "Second Classroom" activities linked to health literacy education in most medical colleges and universities. Currently, most "Second Classroom" activities only involve professional-related services for diagnosis and treatment, disease prevention and voluntary service. Teachers do not do enough research to design the content of health literacy education. The atmosphere of great health teaching is not strong, and the combination of professional education and humanities education is insufficient in depth and breadth.

\section{Ways to Cultivate the Health Literacy of Medical Students}

\section{Immediately Updating the Educational Concept and Combining the "Healthy China" Strategy to Cultivate New Medical Talents}

The main position for the cultivation of health literacy is in schools, and medical colleges should be the bases to take the responsibility to cultivate healthy literacy, highlighting more comprehensive 
professional education and higher levels of humanistic care. We should follow the example of the first "Great Health College in china"- College of Health of Guizhou Medical University, taking advantage of all kinds of health education resources and the academic resources of universities, exploring the possibilities to gradually build majors like health service management, health and disease management, rehabilitation medicine, and medical information engineering to cultivate professional medical talents with strong health literacy from the micro perspective.

Adhering to the education ideas of fully integrating health literacy with the entire process of medical students education to achieve full coverage of the cultivation of health literacy

Besides the professional ethics education, medical students should be guided to correct their attitude towards life and respect for life, to serve the patients as well as the entire people wholeheartedly, to know clearly about the great health ideas of disease prevention and quality of life in the freshman entrance education, and at the same time, a favorable atmosphere should also be created for the cultivation healthy literacy...

Building a health literacy curriculum system, General education lectures should be given in health education, health management and health services with rich teaching content, such as health and disease, health philosophy, health sociology, health psychology, public health management. Elective courses such as Health China Policy, Health Communication, Reproductive Health, Health Aesthetics, Social Organization and Health can also be set up in schools. Teachers of medical colleges should be motivated to combine the health knowledge and health behavior development with professional knowledge teaching together, helping students to form health awareness and health related thinking.

Emphasizing field practice teaching, students are encouraged to experience the important role of health literacy in their field practice such as visiting life science museum and local health development research center, visiting nursing homes and communities, and interning in hospitals, which could help them to learn how to analyze and solve problems with their health literacy.

\section{Carrying out Scientific and Standardized Health Education via New Media}

Taking advantage of the new media era, teachers can recommend new media platforms, such as the authoritative health medical WeChat platform, to students and encourage them to learn health knowledge at any time. At the same time, medical universities can also make full use of the Wechat, Weibo, BBS and other forms of campus media to push health literacy knowledge, health literacy videos and pictures to students, and interact with them via these immediate messengers on health literacy related topics.

\section{Valuing the Importance of "Second Class" in the Cultivation of Health Literacy}

The second course refers to "a series of open activities that focus on educating people, focusing on training students' basic skills and improving students' neutrality, and on the basis of rich resources and space" [6]. The cultivation of health literacy can also be supported by a series of campus activities, including the management of the credit system, so as to increase students' participation.

Actively Organizing Popularization Activities of Health Science Education. Medical universities could conduct a series of activities focusing on topics such as major disease health education, public health knowledge, health behaviors cultivation, and TCM health promotion to further improve medical students' health awareness, the knowledge of related diseases, and strengthen diseases prevention and care ideas. At the same time, collaborating with Propaganda Department and the Student Affairs Office, school hospital of medical university should also conduct health science public opinion monitoring, timely collecting the health science information that affects students and endangers them in large numbers, responding scientifically and publicly.

\section{Organizing Various Social Health-related Social Practices Such as Health-related Poverty Alleviation Activities.}

When medical students participate in social practice activities, they could get a lot of chances to 
apply their health knowledge and skills on the one hand, and on the other hand, they could become more aware of their own health conditions and establish healthy behavioral habits, thereby enhancing health literacy.

Strengthening the Role of "Opinion Leaders" in Health Literacy Cultivation. In the second classroom education, medical universities should take full use of the role of "opinion leaders" and "peer group education". Opinion leaders are key figures in the interpersonal communication network. In medical colleges, opinion leaders refer to the excellent students who are playing a very important role in various student associations and organizations, such as the outstanding student representatives, and class student leaders. They have high prestige and voice among students, good interpersonal relationships, persuasive and influential. They could be motivated to set example of cultivating their own health literacy and use their charisma to positively influence the spread of health information among students.

\section{Acknowledgement}

This research was financially supported by Medical and Humanities Research Center of Xi'an Medical University.

\section{References}

[1] Xi Jinping. The great victory of socialism with Chinese characteristics in the new era: the report of the 19th national congress of the communist party of China.[M]. Peiking: People's publishing house, 2017.

[2] World Health Organization. Division of Health Promotion, Education and Communications. Health Education and Health Promotion Unit. Health Promotion Glossary. Geneva, 1998: 1.

[3] NUTBEAM D. Health literacy as a public health goal: A challenge for contemporary health education and communication strategies into the 21 st century [J]. Health Promot Int, 2000, 15(3).

[4] DUAN Zhi-guang, XIE Jun, ZHENG Jin-ping, et al. Construction of the education mode of medical university's great health humanities [J]. Journal of Chinese Medicine Education., 2016, 36 (6).

[5] GUO Jing, DU Zheng-fang, MA Sha. Survey on health literacy of university students in Beijing [J]. China Health Education., 2011, 27(6)

[6] DING Dan, WANG Zhi-hua. A study on the mode of education in the second classroom of universities [J]. Journal of Hunan Institute of Science and Technology., 2009. 